Editorial Office Notes:

RES-16-803.R1

ORIGINAL ARTICLE

Received 17 November 2016

Invited to revise 31 January 2017

Revised 2 February 2017

Accepted 20 February 2017

Associate Editor: Yuanlin Song

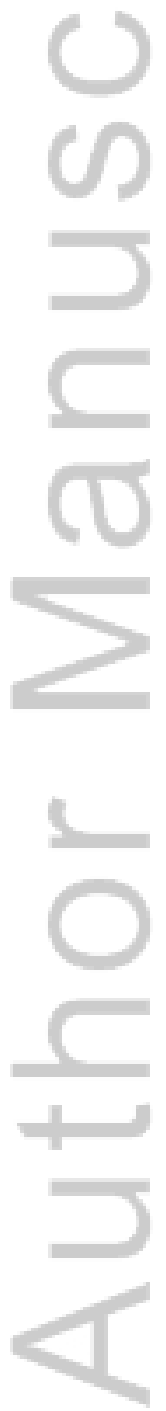

This is the author manuscript accepted for publication and has undergone full peer review but has not been through the copyediting, typesetting, pagination and proofreading process, which may lead to differences between this version and the Version of Record. Please cite this article as doi: $10.1111 /$ resp. 13055

This article is protected by copyright. All rights reserved. 


\title{
ICU mortality is increased with high admission serum osmolarity in all patients other than those admitted with pulmonary diseases and hypoxia
}

\author{
Bihari S, Prakash S, Peake SL, Bailey M, Pilcher D, Bersten AD
}

\section{Authors}

Shailesh Bihari- MBBS, MD, FCICM, PhD

Senior Lecturer, Department of Critical Care Medicine Flinders University

Consultant, Department of Critical Care Medicine Flinders Medical Centre Bedford Park

South Australia 5042

Email: biharishailesh@gmail.com

Shivesh Prakash- MBBS, MD, FCICM, MPH

Lecturer, Department of Critical Care Medicine Flinders University

Consultant, Department of Critical Care Medicine Flinders Medical Centre Bedford Park

South Australia 5042

Email: shivesh.prakash@health.sa.gov.au

Sandra L Peake- MBBS, FCICM, PhD

Associate Professor, School of Medicine, University of Adelaide

Adjunct Associate Professor, ANZIC Research Centre Monash University

Senior Staff Specialist, Department of Intensive Care Medicine, The Queen Elizabeth Hospital, Woodville. South Australia 5011 Australia

Email: Sandra.Peake@health.sa.gov.au

Michael Bailey -BSc, MSc(statistics), PhD

Associate Professor, Australian and New Zealand Intensive Care Research Centre, Department of Epidemiology \& Preventive medicine, Monash University, Melbourne, Australia

Email: michael.bailey@monash.edu 


\section{David Pilcher - MBBS MRCP FRACP FCICM}

Adjunct Clinical Associate Professor ANZIC Research Centre, Department of Epidemiology and Preventive Medicine, Monash University,

Intensivist, The Alfred Hospital;

Chair, Australia New Zealand Intensive Care Society (ANZICS) Clinical Outcomes and Resource Evaluation (CORE) Centre, Melbourne, Australia

Email: D.Pilcher@alfred.org.au

Andrew Bersten- MBBS, MD, FANZCA, FCICM

Professor, Department of Critical Care Medicine, Flinders University

Head of Department, Department of Intensive Care Medicine, Flinders Medical Centre

Bedford Park South Australia 5042

Email: bers0002@flinders.edu.au

\section{Correspondence:}

Shailesh Bihari

Department of ICU, Flinders Medical Centre, Bedford Park, South Australia 5042, Australia Email address: biharishailesh@gmail.com (publishable)

\section{Summary at a glance}

Increased admission serum osmolarity was associated with increased mortality in all patients except in patients with pulmonary diseases and hypoxia where this was not associated with increased odds for ICU mortality.

This article is protected by copyright. All rights reserved. 


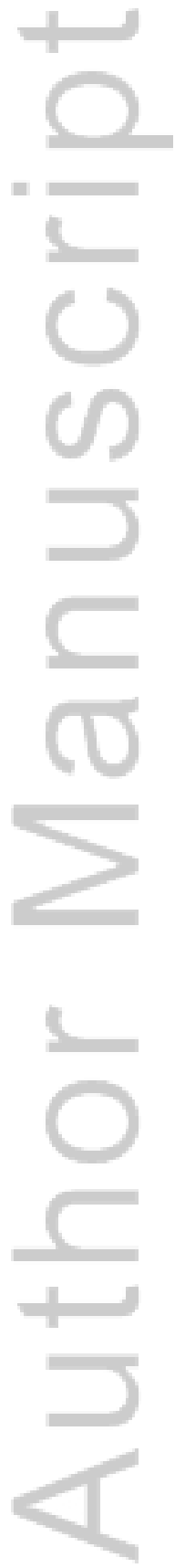

This article is protected by copyright. All rights reserved. 


\section{ABSTRACT}

Background and objective: High serum osmolarity has been shown to be lung protective. There is lack of clinical studies evaluating impact on outcomes such as mortality. We aimed to examine the effect of serum osmolarity on ICU mortality in critically ill patients

Methods: Data from January 2000 to December 2012 was accessed using the ANZICS CORE database. 509,180 patients were included. Serum osmolarity was calculated from data in the first 24 hours of ICU admission. Predefined subgroups (APACHE III diagnostic codes), including patients with acute pulmonary diagnoses, were examined. The effect of serum osmolarity on ICU mortality was assessed with analysis adjusted for illness severity (serum sodium, glucose and urea component removed) and year of admission. Results are presented as odds ratio $(\mathrm{OR})(95 \% \mathrm{Cl})$ referenced against a serum osmolarity of $290-295$ $\mathrm{mmol} / \mathrm{l}$.

Results: The ICU mortality was elevated at each extremes of serum osmolarity (U-shaped relationship). A similar relationship was found in various subgroups, with the exception of patients with pulmonary diagnoses in whom ICU mortality was not influenced by high serum osmolarity and was different from other non-pulmonary sub-groups $(P<0.01)$. Any adverse associations with high serum osmolarity in pulmonary patients were confined to patients with a $\mathrm{PaO}_{2} / \mathrm{FiO} 2$ ratio $>200$.

Conclusion: High admission serum osmolarity was not associated with increased odds for ICU death, in pulmonary patients, unlike other subgroup of patients and could be potential area for a future interventional therapy.

Key Words: serum osmolarity, ICU mortality, pulmonary patients, $\mathrm{PaO}_{2} / \mathrm{FiO}_{2}$ ratio, APACHE III diagnostic codes, serum sodium, serum glucose, serum urea

Short title: Osmolarity doesn't affect lung mortality

This article is protected by copyright. All rights reserved. 


\section{Introduction}

Acute respiratory distress syndrome (ARDS) is a common diagnosis in ICU patients, which bears a high mortality rate ${ }^{1}$. Unfortunately, lung protective ventilation remains the only accepted efficacious treatment strategy so far $^{2}$. Hence the need for novel therapeutics option is imperative. Hyperosmolarity has been shown to be lung protective in multiple experimental and basic science studies of ARDS ${ }^{3-7}$. However, hyperosmolarity has not been associated with better clinical outcomes in patients with lung injury.

Similar to hyperosmolarity, induced hypernatremia has also been shown to be protective in acute lung injury, with proposed mechanisms being a decrease in cellular infiltrate ${ }^{8}$ and preservation of alveolar surfactant ${ }^{9}$. In keeping with this evidence, we observed previously that the phenomenon of increased intensive care unit (ICU) mortality with hypernatremia in an unselected cohort of patients, does not occur in patients with a pulmonary diagnoses, particularly those with $\mathrm{PaO}_{2} / \mathrm{FiO}_{2}$ ratios of less than $200^{10}$. These observations may be simply due to the fact that serum sodium is a major contributor to serum osmolarity.

In the current study we investigated the association of osmolarity with ICU mortality in critically ill patients. The research question was whether the mortality rate that is associated with high admission serum osmolarity, would be relatively lower in ICU patients with an acute pulmonary diagnoses. 


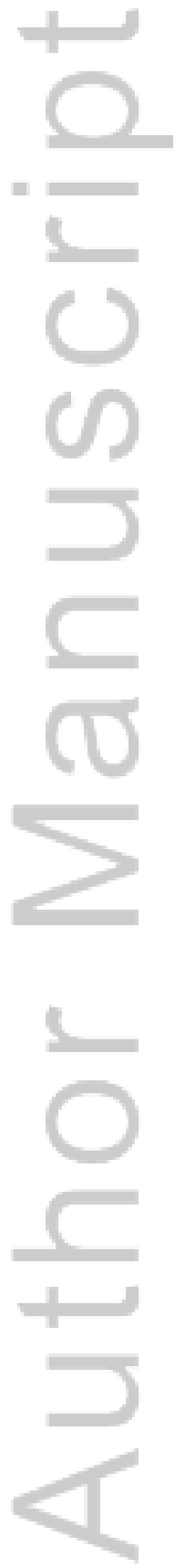

This article is protected by copyright. All rights reserved. 


\section{Methods}

Data from January 2000 to December 2012 was accessed using the Australian and New Zealand Intensive Care Society Adult Patient Database (ANZICS-APD) ${ }^{11}$. During the study period patients with recorded sodium, glucose and urea measurements were included. The data included: age, gender, co-morbidities, physiological variables in the first 24 hours, calculated osmolarity (based on serum sodium, glucose and urea - high and low), ICU admission diagnoses, source of admitted patient - both for hospital and ICU, hospital characteristics, date of admission, ICU and hospital mortality rate and Acute Physiology and Chronic Health Evaluation III score(APACHE III). Study population was analysed by subgroups - : pulmonary and non-pulmonary, medical, surgical, cardiac, neurological, liver, sepsis, ventilated (invasive) and non-ventilated categories (based on APACHE codes). Serum osmolarity was calculated from the highest serum sodium, glucose and urea values within initial twenty four hours of ICU admission. Primary outcome was the effect of serum osmolarity on ICU mortality in patients with or without a pulmonary diagnoses, adjusted for illness severity (serum sodium, glucose and urea eliminated) and year of admission in patients with or without a pulmonary diagnoses. Severity of lung disease in pulmonary patients was stratified by admission $\mathrm{PaO}_{2} / \mathrm{FiO}_{2}$ ratio cut off of 200.

All analyses were performed using SAS version 9.2 (SAS Institute Inc.,Cary,NC,USA). Logistic regression was used to study association between ICU mortality and serum osmolarity (categorical variable with $5 \mathrm{mmol} / \mathrm{l}$ increments). Multivariate models were adapted for centre, admission date, severity of illness and propensity to be admitted with a pulmonary diagnosis. Modified APACHE III risk of death score was obtained after removing components of sodium, glucose and urea. To adjust for potential differences between patients with a pulmonary diagnosis and those without, propensity score for pulmonary diagnosis was calculated for each patient (using logistic regression model and pulmonary diagnosis as the outcome). The propensity model was generated by stepwise selection method (inclusion cut off 
$P<0.01)$. Variables included were: patient source for hospital and ICU, hospital characteristics (level, location and care type), date of admission, age, gender, indigenous status and comorbidities. Results are presented as odds ratios (OR) (95\% confidence intervals; Cl) referenced for a serum osmolarity of $290-295$ $\mathrm{mmol} / \mathrm{l}$. The methodology used was similar to the previously examined admission serum sodium in ICU patients ${ }^{10}$, however besides examining an extended study period (including two additional years of patients information gathering: 2011 and 2012) and a larger cohort of patients, sensitive tests like akaike information criteria for goodness of fit, area under the curve for discrimination and Wald Chi-Square statistic for interaction (all adjusted for site, severity, year \& propensity for pulmonary diagnosis) were used to further differentiate between serum osmolarity and serum sodium as a predictor of ICU mortality for the separation of pulmonary and nonpulmonary patients. Southern Adelaide Human Research Ethics Committee South Australia (\#285.13) approved the research proposal. 


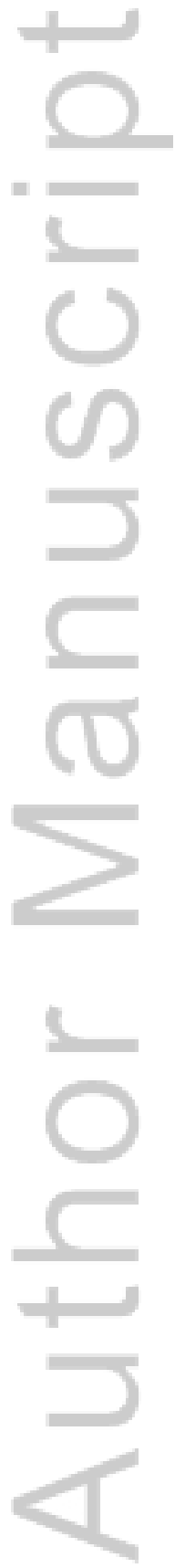

This article is protected by copyright. All rights reserved. 


\section{Results}

Patients aged more than 16 years and admitted to one of the 129 adult ICUs (26\% rural, 22\% metropolitan, 24\% tertiary and $28 \%$ private) in Australia and New Zealand, and with a valid sodium, glucose and urea data, were included. Most of the hospitals $(61 \%)$ had bed capacity of less than 300 , whereas the rest had more than 300 beds. Initial search of the database for the period ranging from year 2000 to 2012 identified 888,519 patients with valid sodium, glucose and urea measurements. Of these, 509,180 patients meeting the screening criteria were included, and the rest were excluded due to missing mortality data $(n=19751)$, missing severity of illness data $(n=75065)$, stay in ICU < 4 hours $(n=18236)$, age $<16$ years $(n=18921)$, transfer to another ICU $(n=2133)$ and readmission during the same hospital admission $(n=175,233)$ (Figure 1).

During the study period there were 55,711 pulmonary and 453,469 non pulmonary patients. The difference between pulmonary and non-pulmonary patient is shown in Table 1. Overall, ICU mortality rate incremented at each extreme of calculated serum osmolarity. A similar relationship was observed in the subgroup populations, except patients with pulmonary diagnoses $(n=55,711)$, in whom ICU mortality rate did not rise with increasing serum osmolarity, and was different from other non-pulmonary sub-groups $(n=453,469)(P<0.001)$ (Figure 2$)$.

Patients with pulmonary diagnoses were subsequently analysed as those with admission $\mathrm{PaO}_{2} / \mathrm{FiO}_{2}$ ratio $<200(\mathrm{n}=26133)$ and $\geq 200(\mathrm{n}=17787)$. The $\mathrm{PaO}_{2} / \mathrm{FiO}_{2}$ ratio had a significant interaction with highest serum osmolarity $(P<0.001)$, suggesting that hyperosmolarity associated mortality was further alleviated with hypoxia in greater severity of respiratory failure $\left(\mathrm{PaO}_{2} / \mathrm{FiO}_{2}<200\right)$ and any adverse associations with high serum osmolarity in pulmonary patients, were confined to patients with a $\mathrm{PaO}_{2} / \mathrm{FiO}_{2}$ ratio $\geq 200$ (Figure 3). Similar results were seen with hospital mortality. 
Serum osmolarity was a stronger predictor of ICU mortality than serum sodium for the separation of pulmonary and non-pulmonary patients as evidenced by the akaike information for goodness of fit criteria (lower = better fit) (174223 vs. 174592; $\mathrm{P}<0.001$ ), area under the curve for discrimination (higher = better discrimination) (0.9154 vs. 0.9148; $\mathrm{P}<0.001)$ and the Wald Chi-Square statistic for interaction (higher $=$ increased significance) $(196$ vs. 149; $\mathrm{P}<0.001)$.

\section{Discussion}

Adjusted ICU mortality, increased at both extremes of osmolarity. However, in contrast, this relationship was not evident among patients admitted with acute pulmonary diagnoses. Unlike patients without pulmonary diagnoses, high serum osmolarity in the first 24 hours of ICU admission was not associated with increased mortality in patients with acute pulmonary diagnoses. This discrepancy was more obvious in patients with severe derangement in oxygenation (admission $\mathrm{PaO}_{2} / \mathrm{FiO}_{2}$ ratio $\leq 200)$.

To our knowledge this is the first clinical data consistent with the lung protective effects of hyperosmolarity found in lab studies ${ }^{3-7,12-15}$. The postulated mechanisms include a decrease in the expression of endothelial leukocyte adhesion molecules ${ }^{3,4}$, attenuation of neutrophil lung sequestration ${ }^{5}$, blockade of pro-inflammatory effects of lipopolysaccharide ${ }^{4,6}$, and remodelling of the endothelial barrier and the actin cytoskeleton, to enhance barrier properties and blockade of pro-inflammatory Pselectin expression ${ }^{7}$. Hyperosmolarity can also up-regulate or down-regulate the transient receptor potential 4 ion channel, which plays a critical role in lung vascular mechanotransduction ${ }^{16}$. Activation of these channels particularly during hypoosmolarity $^{17-21}$, can result in endothelial calcium influx and a rise in pulmonary vascular permeability ${ }^{16}$. Perhaps hyperosmolarity can suppresses these channels, leading to a decrease in pulmonary vascular permeability, which may be beneficial in patients with lung injury. In our study, patients with hypoxia had the maximum benefit from high serum osmolarity. 
Administration of hypertonic saline leads to hyperosmolarity with effective hypertonicity and has been shown to rescue $T$ cell suppression from trauma-induced anti-inflammatory mediators ${ }^{22}$, suppress neutrophil activation ${ }^{23-25}$ and decrease macrophage migration ${ }^{26}$, preserve alveolar surfactant ${ }^{9}$, and attenuate pulmonary neutrophil sequestration ${ }^{8,23,27-31}$; thereby ameliorating lung injury ${ }^{23}$.

Serum sodium is a major contributor to serum osmolarity. In our study, osmolarity was a stronger predictor of ICU mortality than serum sodium for the separation of pulmonary and non-pulmonary patients. However, inducing hypernatremia is the most common, safe and feasible means of achieving hyperosmolarity in the clinical setting. There have been concerns around the association of hypernatremia and mortality in unselected cohort of patients ${ }^{32-37}$. However, based on our results ${ }^{10}$, previous animal studies $s^{8,9,27-31}$ and provided the hypernatremia is induced safely (i.e. shift of less than $12 \mathrm{mmol}$ in 24 hours), we anticipate there will be protective effect of hypernatremia in patients with acute lung injury. There are indirect clinical evidence to support his, in a study examining hypertonic resuscitation in patients with shock after blunt trauma showed improved ARDS-free survival among patients at risk for ARDS with massive transfusion ${ }^{38}$. Similarly in a study examining resuscitation of prehospital post traumatic hypotension, acute lung injury was less common with hypertonic saline/dextran than with normal saline ${ }^{39}$. The current study adds to the hypothesis that inducing hyperosmolarity by carefully inducing hypernatremia will result in amelioration of acute lung injury in critically ill patients. This hypothesis needs to be tested in a prospective controlled study.

\section{Strengths and limitations}

The study examined data from a large cohort of patients $(n=509,180)$, derived from large multinational database. This minimizes bias and improves external validity of the study. The ANZICS database is routinely subjected to internal validation 
processes and on-site audits by trained ANZICS auditors, suggesting that the calculated serum osmolarity values are likely valid. However, there are some limitations. Few patients had to be excluded because of missing data; however, they represented only $11 \%$ of the screened population. Being a retrospective study, interventions to induce high/low serum osmolarity before ICU admission could not be accounted for. Also data around subsequent changes in serum osmolarity (and its potential effect on outcomes) was not available. This should be evaluated in future studies. The broad category of 'pulmonary diagnoses' includes a range of pulmonary conditions, while hyperosmolarity may only benefit patients with lung injury. To study these patients (as these data are not routinely collected), we examined patients presenting with a pulmonary diagnoses and with hypoxia $\left(\mathrm{PaO}_{2} / \mathrm{FiO}_{2} \leq 200\right)$ in the first 24 hours using an interaction model, which revealed reduced risk of mortality with hyperosmolarity. Effect of hyperosmolarity in patients with ARDS should be a evaluated in future study. Finally although serum sodium has been previously examined as a predictor of ICU mortality and its differential effect on patients with respiratory diagnosis ${ }^{10}$, serum osmolarity has never been examined in ICU patients.

This study offers a novel and robust evidence for association between hyperosmolarity and amelioration of mortality risk in patients with pulmonary diseases. Induction of hyperosmolarity could be a potential intervention that needs to be studied further.

\section{Acknowledgements}


We acknowledge the Australia New Zealand Intensive Care Society (ANZICS) and Clinical Outcomes and Resource Evaluation (CORE) Centre for providing the data used in the current study.

\section{Disclosure statement}

Parts of this study were presented at the Annual Meeting of Australian and New Zealand Intensive Care Society (ANZICS) in 2014. Part of the methodology used in the manuscript similar to the previously examined serum sodium with ICU mortality in 2014.

This article is protected by copyright. All rights reserved. 


\section{Figure Legend}

Figure 1: Consort diagram of subjects examined in this study.

The study methodology is similar to the previously examined outcomes with serum sodium ${ }^{10}$

Figure 2: Adjusted odds ratio (shaded lines are 95\% confidence intervals) of ICU mortality relative to $290-295 \mathrm{mmol} / \mathrm{l}$ for different categories of highest serum osmolarity in the first 24 hours in patients with pulmonary (dotted) or without pulmonary diseases (solid). The relationship between osmolarity and ICU mortality was significantly different between pulmonary and non-pulmonary patients $(P<0.001)$ in the first 24 hours of ICU admission.

Figure 3: Adjusted odds ratio (shaded lines are 95\% confidence intervals) of ICU mortality relative to $290-295 \mathrm{mmol} / \mathrm{l}$ for different categories of highest serum osmolarity in the first 24 hours in pulmonary patients with $\mathrm{PaO}_{2} / \mathrm{FiO}_{2}$ ratio $\leq 200$ (dotted) and $\mathrm{PaO}_{2} / \mathrm{FiO}_{2}$ ratio $>200$ (solid). The relationship between osmolarity and ICU mortality was significantly different in pulmonary patients between those with $\mathrm{PaO}_{2} / \mathrm{FiO}_{2}$ ratio $\leq 200$ and $\mathrm{PaO}_{2} / \mathrm{FiO}_{2}$ ratio $>200(\mathrm{P}<0.001)$ in the first 24 hours of ICU admission.

This article is protected by copyright. All rights reserved. 


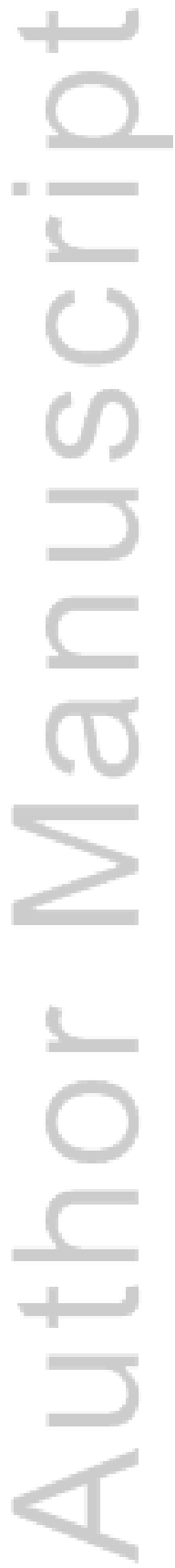

This article is protected by copyright. All rights reserved. 
Table 1: Characteristics and outcomes of patients with non-pulmonary or pulmonary admission diagnoses

\begin{tabular}{|c|c|c|c|}
\hline & $\begin{array}{c}\text { Non-pulmonary } \\
(\mathrm{n}=453,469)\end{array}$ & Pulmonary $(n=55711)$ & p-value \\
\hline Age, mean $\left(S^{*}\right)$ & $61.6(18.2)$ & $61.7(17.9)$ & 0.30 \\
\hline Male gender, number (\%) & $26,8666(59)$ & $30,154(54)$ & $<0.001$ \\
\hline $\mathrm{APACHE}^{\dagger}$ II score, mean (SD) & $15.9(7.6)$ & $18.7(7.8)$ & $<0.001$ \\
\hline APACHE $^{\dagger}$ III score, mean (SD) & $52.8(27.7)$ & $59.6(27.0)$ & $<0.001$ \\
\hline SAPS $^{\ddagger}$ II, mean (SD) & $31.0(16.2)$ & $34.9(15.6)$ & $<0.001$ \\
\hline ICU $^{\S}$ LOS $^{\prime \prime}$ (hrs), median (IQR") & $43.4[22.5-85.7]$ & 76.4 [39.4-161] & $<0.001$ \\
\hline \multicolumn{4}{|l|}{ Physiological variables (first 24 hours) } \\
\hline Highest MAP", mean (SD) & $98.1(16.0)$ & $100.0(16.5)$ & $<0.001$ \\
\hline Highest heart rate, mean (SD) & $99.6(21.8)$ & $113.0(23.2)$ & $<0.001$ \\
\hline Highest temperature $\left({ }^{\circ} \mathrm{C}\right)$, mean $(\mathrm{SD})$ & $37.3(0.8)$ & $37.5(0.9)$ & $<0.001$ \\
\hline Highest sodium (mmol/l), mean (SD) & $140.0(4.5)$ & $139.0(4.9)$ & $<0.001$ \\
\hline Lowest sodium (mmol//,) mean (SD) & $137.0(4.6)$ & $137.0(5.1)$ & $<0.001$ \\
\hline Highest glucose (mmol/l), mean (SD) & $9.7(4.9)$ & $10.2(4.8)$ & $<0.001$ \\
\hline Lowest glucose $(\mathrm{mmol} / \mathrm{l}$,$) mean (SD)$ & $6.6(3.1)$ & $6.8(3.2)$ & $<0.001$ \\
\hline Highest urea (mmol/I,) median (IQR) & $6.2(4.5-9.5)$ & $7.6(5.0-12.1)$ & $<0.001$ \\
\hline Lowest $\mathrm{PaO}_{2} / \mathrm{FiO}_{2}$ ratio mean (SD) & $293(148)$ & $197(115)$ & $<0.001$ \\
\hline ICU mortality, number (\%) & $32632(7)$ & $7351(13)$ & $<0.001$ \\
\hline Hospital mortality, number (\%) & $50985(11)$ & $11392(20)$ & $<0.001$ \\
\hline
\end{tabular}

Some previously reported variable outcomes remained unchanged since $2014^{10}$

This article is protected by copyright. All rights reserved. 
* Standard deviation, ${ }^{\dagger}$ Acute Physiology and Chronic Health Evaluation,$\ddagger$ Simplified Acute Physiology Score, § Intensive Care Unit, || Length of stay, ๆ Interquartile range, ${ }^{* *}$ Mean arterial pressure

\section{References}

1. Bellani G, Laffey JG, Pham T, Fan E, Brochard L, Esteban A, Gattinoni L, van Haren F, Larsson A, McAuley DF, Ranieri M, Rubenfeld G, Thompson BT, Wrigge H, Slutsky AS, Pesenti A; LUNG SAFE Investigators; ESICM Trials Group. Epidemiology, Patterns of Care, and Mortality for Patients With Acute Respiratory Distress Syndrome in Intensive Care Units in 50 Countries. JAMA. 2016; 315:788-800.

2. ARDSN. Ventilation with lower tidal volumes as compared with traditionaltidal volumes for acute lung injury and the acute respiratory distress syndrome. N. Engl. J. Med. 2000; 342, 1301-1308.

3. Rizoli SB, Kapus A, Fan J, Li YH, Marshall JC, Rotstein OD. Immunomodulatory effects of hypertonic resuscitation on the development of lung inflammation following hemorrhagic shock. J. Immunol. 1998; 161:6288-6296.

4. Ochi H, Masuda J, Gimbrone MA. Hyperosmotic stimuli inhibit VCAM-1 expression in cultured endothelial cells via effects on interferon regulatory factor-1 expression and activity. Eur. J. Immunol. 2002; 32:1821-1831.

5. Pascual JL, Khwaja KA, Ferri LE, Giannias B, Evans DC, Razek T, Michel RP, Christou $\mathrm{NV}$. Hypertonic saline resuscitation attenuates neutrophil lung sequestration and transmigration by diminishing leukocyte-endothelial interactions in a two-hit model of hemorrhagic shock and infection. J. Trauma. 2003; 54:121-130.

6. Rabinovici R, Vernick J, Hillegas L, Neville LF. Hypertonic saline treatment of acid aspiration-induced lung injury. J. Surg. Res. 1996; 60:176-180.

7. Safdar Z, Wang P, Ichimura H, Issekutz AC, Quadri S, Bhattacharya J.. Hyperosmolarity enhances the lung capillary barrier. J Clin Invest. 2003; 112:1541-9.

8. Petroni, R. C., Biselli, P. J. C., de Lima, T. M., Theobaldo, M. C., Caldini, E. T., Pimentel, R. N., ... \& Soriano, F. G. (2015). Hypertonic Saline ( $\mathrm{NaCl} 7.5 \%)$ Reduces LPS-Induced Acute Lung Injury in Rats. Inflammation, 1-10.

9. Bihari S, Dixon DL, Lawrence MD, Bersten AD. Induced hypernatraemia is protective in acute lung injury. Respir Physiol Neurobiol. 2016; 227:56-67.

10. Bihari S, Peake SL, Bailey M, Pilcher D, Prakash S, Bersten A. Admission high serum sodium is not associated with increased intensive care unit mortality risk in respiratory patients. J Crit Care. 2014; 29: 948-54.

11. Stow PJ, Hart GK, Higlett T, George C, Herkes R, McWilliam D, Bellomo R; ANZICS Database Management Committee. Development and implementation of a high-quality clinical database: the Australian and New Zealand Intensive Care Society Adult Patient Database. J Crit Care. 2006; 21:133-41. 
12. Quadri, S.K., Bhattacharjee, M., Parthasarathi, K., Tanita, T., Bhattacharya, J. Endothelial barrier strengthening by activation of focal adhesion kinase. Journal of Biological Chemistry. 2003; 278, 13342-13349.

13. Safdar, Z., Yiming, M., Grunig, G., Bhattacharya, J. Inhibition of acid-induced lung injury by hyperosmolar sucrose in rats. American journal of respiratory and critical care medicine 2005; 172, 1002-1007.

14. Shi, H.P., Deitch, E.A., Lu, Q., Hauser, C.J. Hypertonic saline improves intestinal mucosa barrier function and lung injury after trauma-hemorrhagic shock. Shock. 2002; 17, 496501 .

15. Wang, S., Singh, R.D., Godin, L., Pagano, R.E., Hubmayr, R.D. Endocytic response of type I alveolar epithelial cells to hypertonic stress. American Journal of Physiology-Lung Cellular and Molecular Physiology. 2011; 300, L560-L568.

16. Yin J, Kuebler WM. Mechanotransduction by TRP channels: general concepts and specific role in the vasculature. Cell Biochem Biophys 2010;56:1-18.

17. Chen L, Liu C, Liu L. Osmolality-induced tuning of action potentials in trigeminal ganglion neurons. Neurosci Lett 2009;452:79-83.

18. Chen L, Liu C, Liu L, Cao X. Changes in osmolality modulate voltage gated sodium channels in trigeminal ganglion neurons. Neurosci Res 2009;64:199-207.

19. Becker D, Bereiter-Hahn J, Jendrach M. Functional interaction of the cation channel transient receptor potential vanilloid 4 (TRPV4) and actin in volume regulation. Eur $\mathrm{J}$ Cell Biol 2009;88:141-52.

20. Garcia-Elias A, Lorenzo IM, Vicente R, Valverde MA. IP3 receptor binds to and sensitizes TRPV4 channel to osmotic stimuli via a calmodulin-binding site. J Biol Chem 2008;283:31284-8.

21. Mizuno A, Matsumoto N, Imai M, Suzuki M. Impaired osmotic sensation in mice lacking TRPV4. Am J Physiol Cell Physiol 2003;285:C96-C101.

22. Loomis, W.H., Namiki, S., Hoyt, D.B., Junger, W.G. Hypertonicity rescues T cells from suppression by trauma-induced anti-inflammatory mediators. American Journal of Physiology-Cell Physiology 2001; 281, C840-C848.

23. Angle, N., Hoyt, D.B., Coimbra, R., Liu, F., Herdon-Remelius, C., Loomis, W., Junger, W.G. Hypertonic saline resuscitation diminishes lung injury by suppressing neutrophil activation after hemorrhagic shock. Shock 1998; 9, 164-170.

24. Deitch, E.A., Shi, H.P., Feketeova, E., Hauser, C.J., Xu, D.-Z. Hypertonic saline resuscitation limits neutrophil activation after trauma-hemorrhagic shock. Shock. 2003; 19, 328-333.

25. Junger, W.G., Rhind, S.G., Rizoli, S.B., Cuschieri, J., Shiu, M.Y., Baker, A.J., Li, L., Shek,P.N., Hoyt, D.B., Bulger, E.M. Resuscitation of traumatic hemorrhagic shock patients with hypertonic saline-without dextran-inhibits neutrophil and endothelial cell activation. Shock 2012; 38, 341.

26. Kim, J.Y., Choi, S.H., Yoon, Y.H., Moon, S.W., Cho, Y.D. Effects of hypertonic saline on macrophage migration inhibitory factor in traumatic conditions. Experimental and therapeutic medicine. 2013; 5, 362-366. 
27. Murao, Y., Loomis, W., Wolf, P., Hoyt, D.B., Junger, W.G. Effect of dose of hypertonic saline on its potential to prevent lung tissue damage in a mouse model of hemorrhagic shock. Shock. 2003; 20, 29-34.

28. Shields, C., Winter, D., Sookhai, S., Ryan, L., Kirwan, W., Redmond, H. Hypertonic saline attenuates end-organ damage in an experimental model of acute pancreatitis. British journal of surgery. 2000; 87, 1336-1340.

29. Shields, C.J., O’Sullivan, A.W., Wang, J.H., Winter, D.C., Kirwan, W.O., Redmond, H.P. Hypertonic saline enhances host response to bacterial challenge by augmenting receptorindependent neutrophil intracellular superoxide formation. Annals of surgery. 2003; 238,249.

30. Shields, C.J., Winter, D.C., Manning, B.J., Wang, J.H., Kirwan, W.O., Redmond, H.P. Hypertonic saline infusion for pulmonary injury due to ischemia-reperfusion. Archives of Surgery. 2003; 138, 9-14.

31. Vialet, R., Albanèse, J., Thomachot, L., Antonini, F., Bourgouin, A., Alliez, B., Martin, C., Isovolume hypertonic solutes (sodium chloride or mannitol) in the treatment of refractory posttraumatic intracranial hypertension: $2 \mathrm{~mL} / \mathrm{kg} 7.5 \%$ saline is more effective than $2 \mathrm{~mL} / \mathrm{kg} 20 \%$ mannitol. Critical care medicine. 2003; 31, 1683-1687.

32. Darmon M, Diconne E, Souweine B, Ruckly S, Adrie C, Azoulay E, Clec'h C, GarrousteOrgeas M, Schwebel C, Goldgran-Toledano D, Khallel H, Dumenil AS, Jamali S, Cheval C, Allaouchiche B, Zeni F, Timsit JF.. Prognostic consequences of borderline dysnatremia: pay attention to minimal serum sodium change. Critical Care. 2013 17:R12.

33. Palevsky PM, Bhagrath R, Greenberg A. Hypernatremia in hospitalized patients. Ann Intern Med. 1996; 124:197-203.

34. Lindner G, Funk GC, Schwarz C, Kneidinger N, Kaider A, Schneeweiss B, Kramer L, Druml W. Hypernatremia in the critically ill is an independent risk factor for mortality. Am J Kidney Dis. 2007; 50:952-957.

35. Funk GC, Lindner G, Druml W, Metnitz B, Schwarz C, Bauer P, Metnitz PG. Incidence and prognosis of dysnatremias present on ICU admission. Intensive Care Med. 2010; 36: 304-11.

36. Stelfox HT, Ahmed SB, Khandwala F, Zygun D, Shahpori R, Laupland K. The epidemiology of intensive care unit-acquired hyponatraemia and hypernatraemia in medical-surgical intensive care units. Crit Care. 2008;12:R162.

37. Vandergheynst F, Sakr Y, Felleiter P, Hering R, Groeneveld J, Vanhems P, Taccone FS, Vincent JL. Incidence and prognosis of dysnatraemia in critically ill patients: analysis of a large prevalence study. Eur J Clin Invest. 2013 ;43:933-48.

38. Bulger EM, Jurkovich GJ, Nathens AB, Copass MK, Hanson S, Cooper C, et al. Hypertonic resuscitation of hypovolemic shock after blunt trauma: a randomized controlled trial. Arch Surg 2008;143:139-48.

39. Mattox KL, Maningas PA, Moore EE, Mateer JR, Marx JA, Aprahamian C, et al. Prehospital hypertonic saline/dextran infusion for posttraumatic hypotension. The U.S.A. Multicenter Trial. Ann Surg 1991;213:482-91. 
Initial search with the database for the period 2000 to 2012 had 888,519 subjects with recorded sodium, glucose and urea measurements

Exclusion of patients

- Missing mortality data $(n=19751)$

- Missing severity of illness data $(n=75065)$

- Stay in ICU $<4$ hours $(n=18236)$

- Age $<16$ years $(n=18921)$

- Transfer to another ICU $(n=2133)$

- Readmission due to same hospital

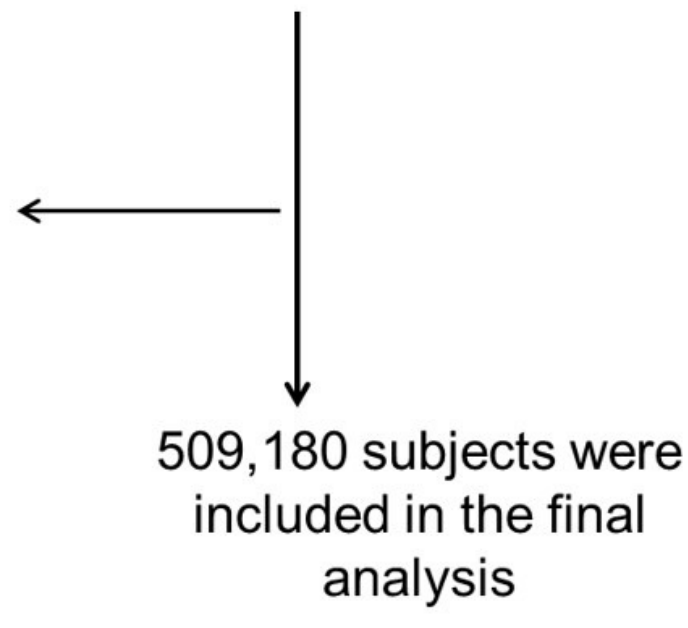
admission $(n=175,233)$

RESP_13055_Fig1.jpg 


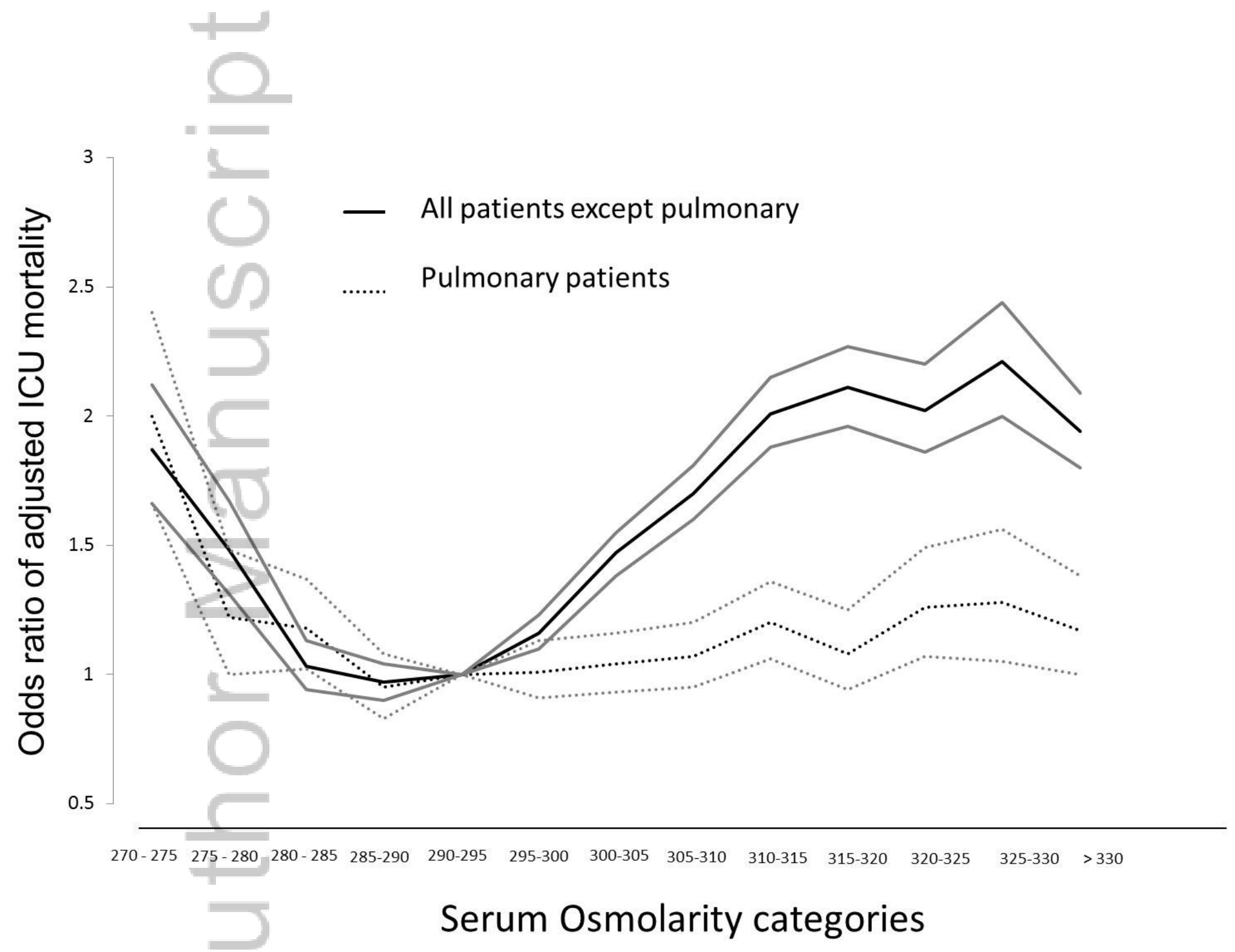

RESP_13055_Fig2.jpg

This article is protected by copyright. All rights reserved. 


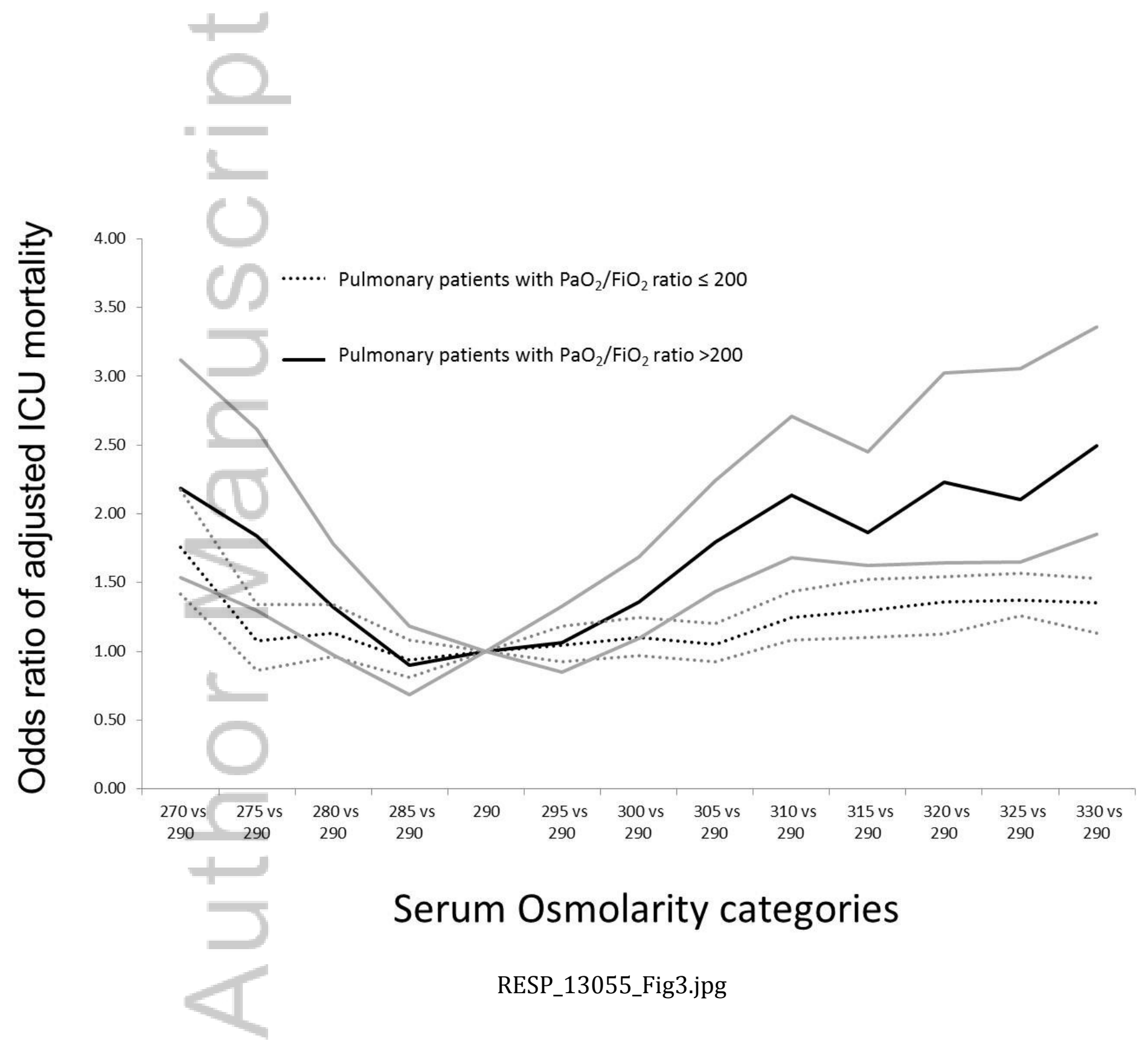

This article is protected by copyright. All rights reserved. 


\section{University Library}

\section{- M I N E R VA A gateway to Melbourne's research publications}

Minerva Access is the Institutional Repository of The University of Melbourne

Author/s:

Bihari, S;Prakash, S;Peake, SL;Bailey, M;Pilcher, D;Bersten, A

Title:

ICU mortality is increased with high admission serum osmolarity in all patients other than those admitted with pulmonary diseases and hypoxia

Date:

2017-08-01

Citation:

Bihari, S., Prakash, S., Peake, S. L., Bailey, M., Pilcher, D. \& Bersten, A. (2017). ICU mortality is increased with high admission serum osmolarity in all patients other than those admitted with pulmonary diseases and hypoxia. RESPIROLOGY, 22 (6), pp.1165-1170. https:// doi.org/10.1111/resp. 13055.

Persistent Link:

http://hdl.handle.net/11343/292771 